fitted into the scientific officer scale. This means that, unlike the directors of other national museums, the director is graded as a chief scientific officer. This does not seem to affect his salary one way or another; he will get a salary of $£ 5,375$, which seems to be the same as the salaries of the directors of, for example, the Science Museum and the Victoria and Albert Museum. The director and principal librarian of the British Museum naturally receives a little more-he gets $£ 5,550$, and is responsible to the trustees for managing

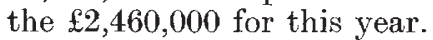

\section{Brains and Behaviour}

European students of the brain tend to meet each other most often at conferences held in the United States. There is at present no organization equipped to convene regular symposia on the brain in Europe, where meetings would be cheaper and more frequent, and Europeans who work in the field have come to feel out of touch with one another's work.

To repair this lack of communication it is proposed to form a European Brain and Behaviour Society. The present intention of the society is "to further scientific enquiry within those fields that bear on the interrelationships between brain and behaviour"; to this end it will hold meetings for discussion and the reading of papers and disseminate information. A study group is to meet in Rotterdam early next year to define further the aims of the society and to elect its first membership. All persons interested in joining are invited to write to Dr A. Cowey at the Institute of Experimental Psychology, South Parks Road, Oxford, stating their field of interest and qualifications, together with any suggestions they may have about the general aims of the society.

The idea of the society originated in a meeting of scientists called by the Organization for Economic Cooperation and Development (OECD) last year to discuss the field of the neurosciences. The opinion at the meeting was that organizational facilities in Europe were poorly equipped to support the expansion of what is considered to be a fast growing subject. The sponsors of the proposed society are K. Akert (Zurich), A. Cowey (Oxford), M. Frankenhaeuser (Stockholm) H. G. J. M. Kuypers (Rotterdam), J. Paillard (Marseilles), D. Ploog (Munich), J. Scherrer (Paris) and L. Weiskrantz (Oxford).

\section{Spectacles for Life}

A PAIR of variable refraction spectacles has been developed by $\mathrm{Dr}$ B. M. Wright of the Engineering Division at the National Institute for Medical Research at Mill Hill. Instead of the conventional solid lenses of existing spectacles, the lenses are hollow, with thin flexible walls, and are filled with a nearly saturated solution of calcium bromide which has a suitable refractive index. The volume of the lenses is changed by pumping the liquid in and out in order to change the curvature of the flexible wall. This is accomplished by means of a simple cylinder and piston with a rubber ring seal. The piston is operated by a slide in one side piece of the spectacles, the cylinder being housed in a cavity on the inside. Because these spectacles can be continuously adjusted as the need arises, one pair should, in theory, last a lifetime, and should therefore be much cheaper than existing spectacles. Dr Wright has been wearing a pair of these spectacles for more than three months with no complaints, but their durability remains to be proved.

This was one of the exhibits at a recent visit to the institute. In the Division of Parasitology, Drs S. R. Smithers, R. J. Terry and D. J. Hickley claim to have discovered how the parasite causing schistosomiasis avoids rejection by the human body. Using immunological techniques, they have shown that the parasite somehow sticks host antigenic material onto itself so that it is not recognized as "non-self" by circulating antibodies. According to the three research workers, this "disguising" phenomenon may explain why the parasite can persist in the human body for up to 20 years in what ought to be an immunologically hostile environment.

An interesting proposal for the structure of ribosomes was put forward by Dr R. A. Cox, who illustrated his talk with models built within the department. Sir Peter Medawar, director at Mill Hill, hopes to see a department at the institute which correlates physiology of the central nervous system with behaviour. Because, however, different animals have been used so far for behavioural studies from the ones used for physiological studies, Dr B. Delisle Burns has a difficult task ahead. At present, he and other members of the Division of Physiology and Pharmacology are studying the way in which neurones in the brain respond to patterns of light falling on the eyes. Information about the disturbance set up in the brain in this way could prove useful to the practice of ophthamology, particularly in connexion with the treatment of strabismus-or, put more plainly, squint.

\section{Accident Prevention}

More than 7,000 people died in traffic accidents last year in Britain and nearly 94,000 were seriously injured, with the numbers increasing more quickly than the mileage travelled. The causes and possibie preventive measures were the subject of a recent conference at Cranfield on vehicle and road design, sponsored jointly by the Institution of Mechanical Engineers and the Advanced School of Automobile Engineering. This is one of the few occasions on which vehicle and road designers have met to discuss their common problem-the car and its driver.

A police traffic superintendent is reported to have said that the defect which causes nearly every accident lies in "the nut holding the wheel". One contributor pointed out that road engineers should not assume that drivers are omniscient. "If asked to make more than one decision at a time, they will fail; if' faced with a situation which can be misinterpreted, someone will eventually find the wrong meaning."

The effect of human fallibility is easily apparent in the statistics for traffic accidents during the last three months of 1967 in Britain, after the breathalyser test came into operation; during this period, driver and passenger casualties fell by 19 per cent, motor cyclist casualties by 16 per cent and pedal cyclists by 14 per cent. But drivers are not altogether to blame; nearly half of all serious accidents in Britain take place at uncontrolled junctions, and at some intersections accidents have fallen by 40 per cent when traffic lights have been installed. Professor R. J. Smeed of University 
College, London, estimated that roundabouts reduce accidents by 60 per cent. R. L. Moore of the Road Research Laboratory emphasized that "police, magistrates, road engineers and road users in general should not assume that because visibility is good in the sense that there are no physical obstructions, a driver can, or should, be able to see everything. . . . When at some point in the road system drivers fail consistently, the system needs examination rather than the driver".

Motorway travel has proved to be the safest in England, with only 0.7 accidents per million vehicle miles compared with $1 \cdot 6$ accidents per million vehicle miles on rural dual carriageways or $2 \cdot 1$ on rural threelane carriageways, but there have been several multiple crashes, usually during periods of decreased visibility. Since most motorists expect free flow on a motorway, they are not at their most alert and are not prepared for obstructions. To deal with this problem, more comprehensive signalling is being installed, the first on the Severn Bridge section of the M4. A similar experiment on the John Lodge Freeway in the United States is supposed to have reduced journey times by 5 to 25 per cent.

\section{Saving York Minster}

Display boards showing the progress of an appeal for restoration funds are a familiar sight outside churches throughout Britain. The largest appeal of this kind was launchod just over a year ago by York Minster,

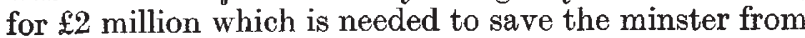
collapse. About three-quarters of this amount has already been raised. The fabric of York Minster has long becn under superficial repair to renew decayed stonework-the scaffolding which for years enclosed the west end is evidence of this-but the discovery

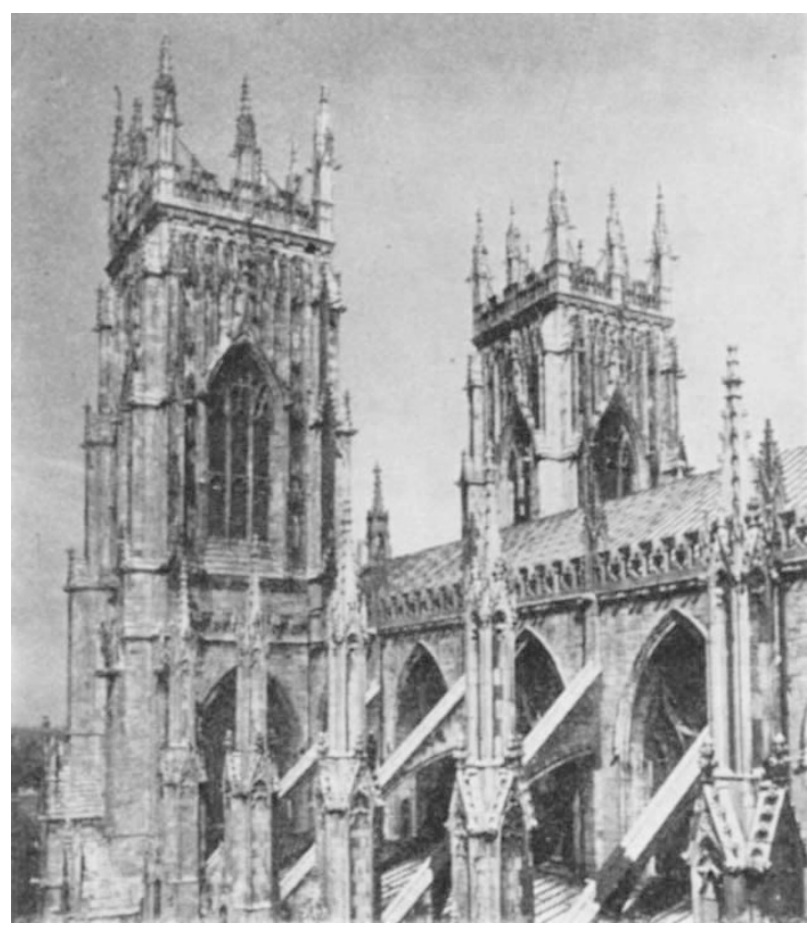

York Minster-some of the roof and facing which is in urgent need of repair. that the building was actually in danger of collapse was made quite recently. A thorough survey of the minster was carried out in 1965 and 1966 , when ominous cracks were found in the piers supporting the massive central tower, and in part of the choir. On the pretext of an archaeological dig, an excavation to the foundations of the tower was made to look for the cause of the trouble. The problem seems to be that the twelfth century foundations of the minster are just not strong enough to support the weight of the tower, added early in the fifteenth century. The foundations of the tower itself are four massive piers which have to stand up to stresses reaching $\mathbf{4 6}$ tons per square foot-more than three times the maximum permitted by current building codes and greater than the crushing strength of the

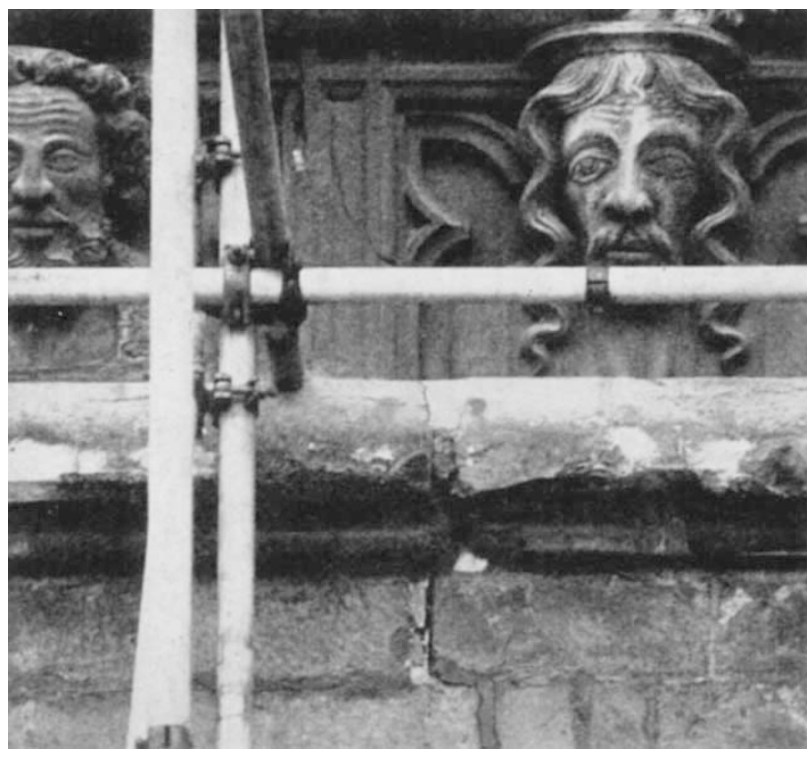

A crack which threatens the great east window.

mortar binding the blocks together. It is hardly surprising that the foundations are bulging under the pressure from above.

'Ihis comparatively recent deterioration in the condition of the minster is likely to have its origin in the improvement in the drainage in the York area over the past century. Since the last examination of the foundations in 1837, the water table in the glacial material on which the minster rests has sunk by $4 \mathrm{ft}$. This means that the foundations, which used to be supported to some extent by waterlogged soil, are now free to bulge under the excessive pressure. Work is now going on to strengthen the foundations of the central tower by the insertion of steel struts between the four piers, and the construction of concrete rafts to spread the weight of the tower over a larger area.

To arrest the deterioration of the superstructure of the tower, it is to be surrounded by a steel girdle at the level of the roof of the nave and a reinforced concrete ring beam is to be fitted at the top. The tendency for the tower to collapse has caused the east wall of the minster, which includes a Perpendicular window containing some magnificent stained glass, to lean outwards by up to about two feet. To save this part of the minster, massive steel shoring is being erected.

It is clearly going to be several years yet before the 